\title{
A noninvasive electromyographic study on threshold and intensity of cough in humans
}

\author{
G.A. Fontana*, T. Pantaleo**, F. Lavorini*, V. Boddi+, P. Panuccio*
}

A noninvasive electromyographic study on threshold and intensity of cough in humans.
G.A. Fontana, T. Pantaleo, F. Lavorini, V. Boddi, P. Panuccio. @ERS Journals Ltd 1997.

ABSTRACT: The assessment of cough threshold and intensity is important in respiratory medicine. We have developed a method for objectively and noninvasively assessing cough threshold and intensity of expiratory muscle efforts in response to inhalation of ultrasonically nebulized distilled water (UNDW).

Thirty (83\%) out of 36 volunteers studied coughed in response to UNDW inhalation. Cough threshold was taken as the lowest nebulizer output $\left(\mathrm{mL} \cdot \mathrm{min}^{-1}\right)$ that induced cough in two challenges performed at a $30 \mathrm{~min}$ interval. At threshold level, repeatability of peak and slope of the integrated electromyographic (IEMG) activity of abdominal muscles was evaluated. Short- and long-term repeatability of cough threshold were evaluated in 15 subjects following a $3 \mathrm{~h}$ and a $6-9$ month interval, respectively. Dose-response relationships between nebulizer outputs and IEMG-related variables were also investigated, as were the correlations between the latter and expiratory flow during voluntary coughing.

The median (1st and 3rd quartile) cough threshold value was 0.89 (0.40 and 1.54) $\mathrm{mL} \cdot \mathrm{min}^{-1}$. At threshold level, peak and slope of IEMG activity were highly reproducible. Cough threshold displayed a high degree of short- and long-term repeatability. Peak and slope of IEMG activity displayed a clear trend to increase $(p<0.01)$ following inhalation of progressively higher UNDW outputs. Maximum flow during voluntary coughs of varying intensity correlated with the peak $(p<0.05)$ and, more closely, with the slope $(\mathbf{p}<\mathbf{0 . 0 1})$ of abdominal IEMG activity.

The assessment of cough threshold as well as the evaluation of the intensity of cough efforts by abdominal integrated electromyographic recordings may represent useful and reliable tools for cough research in humans. Eur Respir J 1997; 10: 983-989.

\begin{abstract}
*Dipartimento di Fisiopatologia Clinica, Sezione di Fisiopatologia Respiratoria, **Dipartimento di Scienze Fisiologiche, and +Istituto di Patologia Generale, Università di Firenze, Florence, Italy.
\end{abstract}

Correspondence: G.A. Fontana Dipartimento di Fisiopatologia Clinica Sezione di Fisiopatologia Respiratoria Viale G. B. Morgagni 85

50134 Firenze

Italy

Keywords: Abdominal muscles airways

cough

electromyography

ultrasonically nebulized distilled water

Received: November 61995

Accepted after revision January 101997

This work was supported by grants from the Ministero dell'Università e della Ricerca Scientifica e Tecnologica of Italy.
Cough is an important defence mechanism; its main function is to remove mucus and/or foreign bodies from the respiratory tract by generating high expiratory flow. Objective assessment of cough is important for the understanding of the neural mechanisms of cough in normal subjects and in patients.

Several nebulized agents have been employed experimentally to elicit cough. They include citric acid, capsaicin, histamine, bradykinin and prostaglandins [1-5], as well as ultrasonically nebulized distilled water (UNDW) and solutions low in permeant anion content [1, 6-11]. One of the most valuable indices of a subject's susceptibility to cough stimuli may be represented by the cough threshold [8-10], which has been employed in studies aimed at evaluating the separate role of osmolarity and ion content of inhaled water solutions both in normal subjects and asthmatic patients [8,9]. During UNDW or low-chloride challenges, cough response has frequently been assessed in terms of cough frequency, i.e. the number of expiratory thrusts during the inhalation period $[6,7,11]$. This method, however, treats all coughs as equal and does not allow a quantitative evaluation of the intensity of the cough motor response in terms of strength of expiratory muscle contraction and, hence, of force or pressure generated by them. Such evaluation is of particular interest in patients who are expected to have an impaired motor performance, namely those with neurological or muscular disorders.

Very few attempts have been made to develop objective, noninvasive methods to assess the intensity of the muscle response during cough challenges. Few data have been derived from the quantitative analysis of the response based solely on variables such as expiratory flow and volume [2, 6]. Cox et al. [2] developed a method to assess the intensity of cough by recording electromyographic (EMG) activity of abdominal muscles. They used fullwave rectified EMG activity passed either through a lowpass resistance-capacitance (RC) filter (time averaged EMG) usually referred to in the literature as "moving average" or "integrated" EMG (IEMG) activity, or through an integrating circuit capable of providing the integrated sum of the total electrical activity ("true" integrated activity). This latter, simply defined as integrated EMG, was claimed to be a reliable measure of cough intensity, since it weakly correlated with cough volume and cough noise and, even less convincingly, with cough flow. 
The present study was undertaken in normal subjects with two aims. Firstly, to validate a method for evaluating cough threshold and its short- and long-term repeatability using UNDW inhalation, a stimulation technique that, in our experience, proved to be particularly wellaccepted both by normal subjects and patients with respiratory diseases. Secondly, to reconsider the use of IEMG activity of abdominal muscles in the noninvasive assessment of the intensity of muscular efforts during coughs, produced either voluntarily or reflexly.

Preliminary accounts of the present work have already been published in abstract form [12].

\section{Methods}

\section{Subjects}

Thirty six healthy nonsmokers volunteered for the study, but only the 30 who coughed in response to preliminary UNDW inhalation challenges were selected. They included 24 males and 6 females, aged 25-68 yrs (mean $38 \mathrm{yrs}$ ), and none of them had suffered from respiratory tract infections in the preceding 6 weeks. The experimental protocol adhered to the Recommendations of the Declaration of Helsinki for Human Experimentation. Individual informed consent was obtained after detailed explanation of the procedure, but not of the purpose, of the study.

\section{Aerosol production}

The UNDW was produced by a Mist-O ${ }_{2}$-Gen EN143A ultrasonic nebulizer (Mist-O ${ }_{2}$-Gen Equipment Co., Oakland, CA, USA). Prior to each challenge, the jar of the nebulizer was filled with $180 \mathrm{~mL}$ of distilled water. The airflow from the nebulizer was constant, at $14 \mathrm{~L} \cdot \mathrm{min}^{-1}$. The output of the nebulizer was conveyed to a $1.5 \mathrm{~L}$ reservoir bottle to ensure constant aerosol supply with each breath. The nebulizer output could be adjusted by means of a potentiometer and monitored as a direct current (DC) signal on an oscilloscope. In preliminary trials (five experiments) the actual nebulizer output was determined by progressively increasing it in steps corresponding to $5 \%$ of the maximum attainable DC signal. The reproducibility of UNDW output was checked by weighing the water content of the nebulizer before and after each $1 \mathrm{~min}$ nebulization period, performed at each subsequent $5 \%$ step. Variances calculated for each set of experiments were homogeneous ( $\mathrm{p}=0.49$, Cochran's C-test); the relationship between nebulizer output and the corresponding DC signal was analysed by least squares regression. The relationship fitted with the linear model $(\mathrm{r}=0.95 ; \mathrm{p}<0.001)$ and mean nebulizer output $\left(\mathrm{mL} \cdot \mathrm{min}^{-1}\right)$ could be calculated according to the following equation:

$$
\begin{gathered}
\text { nebulizer output }\left(\mathrm{mL} \cdot \mathrm{min}^{-1}\right)=-1.90+0.066 \times \% \text { of } \\
\text { maximum DC signal }
\end{gathered}
$$

The range of nebulizer outputs (mean values) employed in the present experiments was $0.08-4.45 \mathrm{~mL} \cdot \mathrm{min}^{-1}$, i.e. $30-100 \%$ of the maximum DC signal. The mass median aerodynamic diameter (MMAD) of aerosol particles generated by this nebulizer has been reported to be 5.7 $\mu \mathrm{m}$, with a geometric standard deviation of $1.4 \mu \mathrm{m}$ [13].

\section{Recording procedures and protocol}

In all participants, the EMG activity was recorded from the abdominal muscles, using surface $\mathrm{Ag}-\mathrm{AgCl}$ electrodes positioned along the line of right obliquus externus fibres, with the lower medial electrode 10-20 $\mathrm{mm}$ lateral to the edge of the rectus sheath and just above the level of the umbilicus. The EMG activity recorded with these electrodes during cough was considered to reflect the activation of the obliquus externus muscle, as well as the activity of deeper abdominal muscles, namely the transversus [14], with minimal contamination of the EMG signal by the rectus abdominis electrical activity, as judged by the ability of different voluntary tasks to activate these muscles preferentially [15]. In addition, the rectus abdominis muscle has been shown to play only a minor role in coughing [16].

The EMG signals were amplified, full wave rectified, and passed through a "leaky" integrator (low-pass RC filter, time constant $50 \mathrm{~ms}$ ) to obtain a "moving average" of the activity, or "integrated" EMG (IEMG) activity. Prior to each challenge, subjects were asked to change their posture (trunk flexion) and to simulate events such as sighing and throat-clearing; the IEMG waveforms of these manoeuvres were compared with those recorded during voluntary coughing for differentiation. On paper recordings (see below) at relatively high speed $\left(25 \mathrm{~mm} \cdot \mathrm{s}^{-1}\right)$, we measured the peak IEMG activity (IEMGp) and the duration of the expiratory IEMG ramp during cough ( $t \mathrm{EC})$, taken as the time interval between the onset of IEMG activity and IEMGp (fig. 1a). The onset of IEMG activity was arbitrarily considered as the time at which the activity just exceeded $10 \%$ of its peak amplitude above the mean level of ongoing baseline activity. When a tonic level of baseline activity was present, it was not included in the measurement of peak amplitude. The $10 \%$ level was chosen to avoid uncertainties in the measurements, especially when slow drifts in IEMG activity were present.

In all experiments, subjects were comfortably seated on a dentist's chair, and were repeatedly reminded to relax and breathe normally with as constant a pattern as possible. After a few minutes of rest, they were requested to cough as forcefully as possible (single coughs at 5-10 s intervals) until IEMG activity from abdominal muscles during 15-20 cough efforts was recorded. Three to five maximum static expiratory manoeuvres were also performed by each subject, in accordance with standard criteria [17]. Following a $10 \mathrm{~min}$ recovery period, each subject was connected to the nebulizer via a mouthpiece and, during resting tidal breathing, inhaled increasing UNDW concentrations obtained by adjusting the nebulizer output. To avoid rebreathing, an outlet proximal to the patient port of the apparatus was provided. In all instances, the UNDW inhalation time was standardized at $1 \mathrm{~min}$ for each nebulizer output; 2-3 min of rest were scheduled between steps. On appearance of cough, the test was discontinued and subjects were allowed to recover for at least $30 \mathrm{~min}$ to avoid tachyphylaxis [1].

The challenge was then restarted with inhalation of the UNDW produced at the output step immediately below the first cough threshold. If cough could be elicited again at the same level which had previously been 


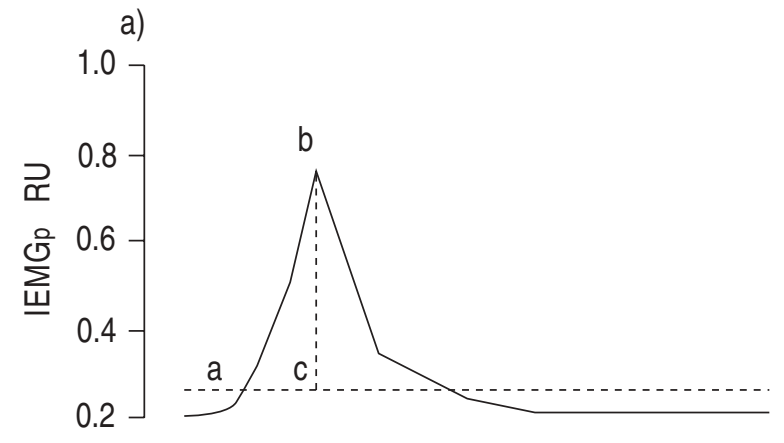

b)

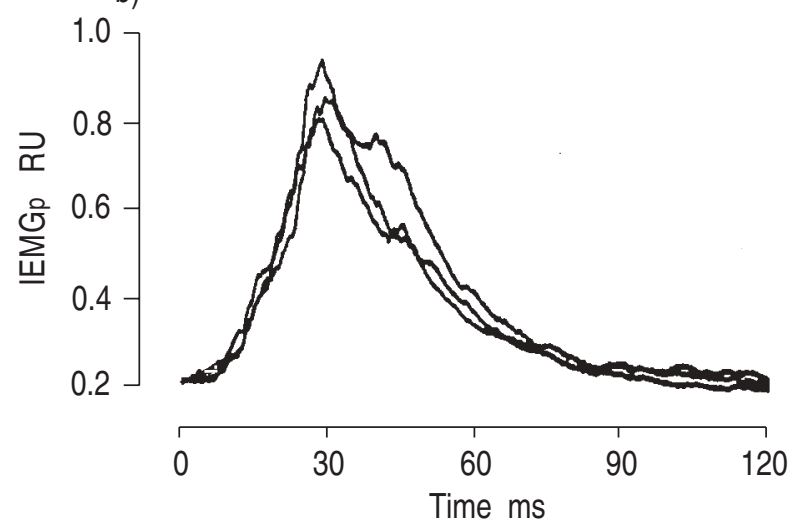

Fig. 1. - Cough-related IEMG events induced by UNDW inhalation at threshold level. a) Diagrammatic representation of a single IEMG trace. The dashed horizontal line indicates the level corresponding to $10 \%$ of the total IEMG peak amplitude (see Methods). The segment "bc" was taken as a measure of IEMGp, and the segment "ac" as a measure of $t \mathrm{EC}$. The slope of the expiratory ramp was calculated as the ratio between "bc" and "ac". b) superimposed traces of IEMG activity recorded during three cough events in one subject. RU: relative units; IEMG: integrated electromyographic; UNDW: ultrasonically nebulized distilled water; IEMGp: peak IEMG activity of abdominal muscles; $t \mathrm{EC}$ : duration of the IEMG ramp.

shown to evoke cough, the challenge was discontinued, and that level taken as the subject's cough threshold. Conversely, if no cough response could be obtained, the challenge was resumed and continued until cough could be elicited twice at the same nebulizer output. In only two experiments was a difference found between cough threshold values measured on the first and second occasion. This finding validated the choice of a 30 min interval between challenges to avoid tachyphylaxis. Thus, cough threshold was taken as the lowest UNDW output capable of evoking at least one cough during two distinct challenges, separated by a time interval of approximately $30 \mathrm{~min}$. This procedure ensured that the cough recorded was a reflex response to the challenge rather than a random event. For each of these two UNDW inhalation periods required to assess cough threshold, mean IEMGp was measured. The mean value of IEMGp/t $\mathrm{EC}$ (i.e. the rate of rise or slope of IEMG activity) was subsequently calculated (fig. 1a).

To evaluate both short- and long-term repeatability of cough threshold, this variable was reassessed in 15 subjects after a $3 \mathrm{~h}$ and a 6-9 month interval, respectively. In another group of nine subjects, we investigated whether maximum expiratory flow $\left(V^{\prime} \max \right)$ correlated with IEMGp and IEMGp/tEC during voluntary cough efforts. In fact, the force developed by contracting muscles and responsible, in the present circumstances, for the expiratory driving pressure is proportional to the related IEMG activity $[18,19]$. Thus, expiratory flow should vary as a function of the maximum IEMG value attained during contraction (IEMGp) and the rate of its development (IEMGp/tEC), especially during the approximately fixed time $(0.2 \mathrm{~s})$ of the compressive phase of the cough [20]. In these runs, subjects were instructed to cough (20 efforts) at an intensity varying at random from the lowest to the maximum attainable cough effort. Airflow was monitored continuously by having the subjects wear a noseclip and breathe through a mouthpiece connected to a heated Fleisch No. 4 pneumotachograph.

At least $30 \mathrm{~min}$ after the completion of the procedures required for the assessment of the cough threshold [1], an attempt was also made to investigate the dose-response relationship between cough stimulus intensity and the magnitude of IEMG-related variables in the same subjects. To this end, the subjects inhaled progressively increasing UNDW outputs, starting from the previously determined threshold level $\left(\mathrm{T}\right.$; in $\left.\mathrm{mL} \cdot \mathrm{min}^{-1}\right)$. The other inhaled outputs were $1.3 \times \mathrm{T}, 1.6 \times \mathrm{T}$ and $1.9 \times \mathrm{T}$. The latter UNDW output corresponded in some subjects to values equal or close to the maximum attainable nebulizer output. The procedure of expressing stimulus intensity as a multiple of individual cough threshold values made it possible to take into account the subject's sensitivities to UNDW and pooling of data for statistical analysis. Each nebulizer output was inhaled for $1 \mathrm{~min}$, with a 30 min interval between inhalation periods. The signals of all recorded variables were fed to an eight-channel chart recorder (HP 7758A; Hewlett and Packard, Palo Alto, CA, USA; paper speed 5-25 $\left.\mathrm{mm} \cdot \mathrm{s}^{-1}\right)$ and to a frequency modulated (FM) tape recorder (HP 3960) for later analysis.

\section{Data analysis}

The shape of the distribution of the cough threshold values observed was assessed by the Wilk-Shapiro test for normal distribution. Peak IEMG activity recorded during UNDW-induced cough was measured in arbitrary units, and always expressed as a fraction of mean IEMGp values observed during maximum voluntary cough (relative units (RU)). In all subjects, for each of the two challenges required for the assessment of cough threshold, average IEMGp was considered. Furthermore, to assess repeatability of IEMGp and IEMGp/tEC, at the threshold level, the statistical method devised by BLAND and Altman [21] was used. Briefly, individual differences between values of each variable obtained during the two successive UNDW inhalation periods required to determine cough threshold were calculated, and the normality of their distribution was checked. The mean and the SD of these differences were calculated. Paired t-tests were subsequently used to ascertain that differences did not significantly differ from zero; individual differences were then plotted against their means. Ninety five percent of differences are expected to be $<2$ $\mathrm{SD}$; this is the definition of a repeatability coefficient adopted by the British Standards Institution [21]. Thus, repeatability was accepted when $95 \%$ of differences proved to be less than twice the SD of the differences between pairs of repeated observations [21]. 
The same statistical procedure was employed to analyse repeatability of cough threshold in the 15 subjects selected for this purpose. Spearman's nonparametric correlation coefficient $\left(r_{s}\right)$ was used to investigate relationships of cough threshold versus IEMGp and IEMGp/t EC (mean values of the two challenges performed to define cough threshold) during the corresponding cough challenges, as well as of $V^{\prime}$ max versus IEMGp and IEMGp/t EC during voluntary cough efforts. Wilcoxon's signed rank tests were used to compare correlation coefficients as well as IEMG variables during cough, either voluntarily or reflexly produced. For each participant in the dose-response studies, the relationship between the intensity of the cough stimulus, expressed as a multiple of cough threshold, and the magnitude of IEMG variables was analysed by linear regression analysis. The mean regression coefficient and $\mathrm{p}$-value for pooled data were also calculated. Reported values are mean \pm SD, unless otherwise stated. In all instances, a p-value less than 0.05 was taken as significant.

\section{Results}

Cough threshold values, i.e. the lowest nebulizer outputs that proved to be effective in inducing a cough response $(\mathrm{n}=30)$, ranged $0.40-3.0 \mathrm{~mL} \cdot \mathrm{min}^{-1}$ and corresponded to nebulizer settings between 35 and $75 \%$ of the maximum output attainable. Cough threshold values were not normally distributed $(\mathrm{p}<0.01)$; thus, for this variable, instead of the mean value $\pm \mathrm{SD}$, we report the median and, as indices of variability, the 1st and 3rd quartile as well as the interquartile range. Median cough threshold value was $0.89 \mathrm{~mL} \cdot \mathrm{min}^{-1}$, with a $1 \mathrm{st}$ and $3 \mathrm{rd}$ quartile of 0.40 and $1.54 \mathrm{~mL} \cdot \mathrm{min}^{-1}$, and an interquartile range of $1.14 \mathrm{~mL} \cdot \mathrm{min}^{-1}$. In the remaining six subjects, cough was not elicited, even with the highest nebulizer output available.

During control breathing, none of the subjects had EMG activity in the abdominal muscles. However, obvious EMG activity was consistently recorded from these muscles during maximum static expiratory manoeuvres, as well as during voluntary and reflex cough efforts. Average pressure recorded during maximal static expiratory manoeuvres, expressed as percentage of predicted values, was $96 \pm 8 \%$. Mean IEMGp values during maximum voluntary cough slightly, but nonsignificantly, exceeded $(5 \%)$ those obtained during maximum static expiratory manoeuvres.

Representative recordings of cough-related IEMG events induced by UNDW inhalation at threshold level in one subject are illustrated in fig. 1b. When considering average data from all the subjects, obtained during the first and second UNDW inhalation period, we found that IEMGp values (expressed as a fraction of those recorded during maximum voluntary cough) were $0.82 \pm 0.22$ and $0.83 \pm 0.16$, respectively; the corresponding values of IEMGp/tEC, were $0.69 \pm 0.33$ and $0.75 \pm 0.35$. The mean differences calculated were $-0.01 \pm 0.022$ and $-0.06 \pm 0.21$, respectively. Thus, since mean differences between the values of each variable were not significantly different from zero, data were considered suitable to assess repeatability [21]. According to the statistical procedure employed, repeatability was accepted when no more than $5 \%$ of calculated differences exceeded the coefficient of repeatability. None of the differences in IEMGp and IEMGp/tEC (average value for each trial) exceeded the coefficient of repeatability, and more than $50 \%$ of them were grouped within one SD (fig. 2). No correlation was found $\left(r_{s}=0.066 ; p=0.74\right)$ between individual threshold values and the corresponding IEMGp
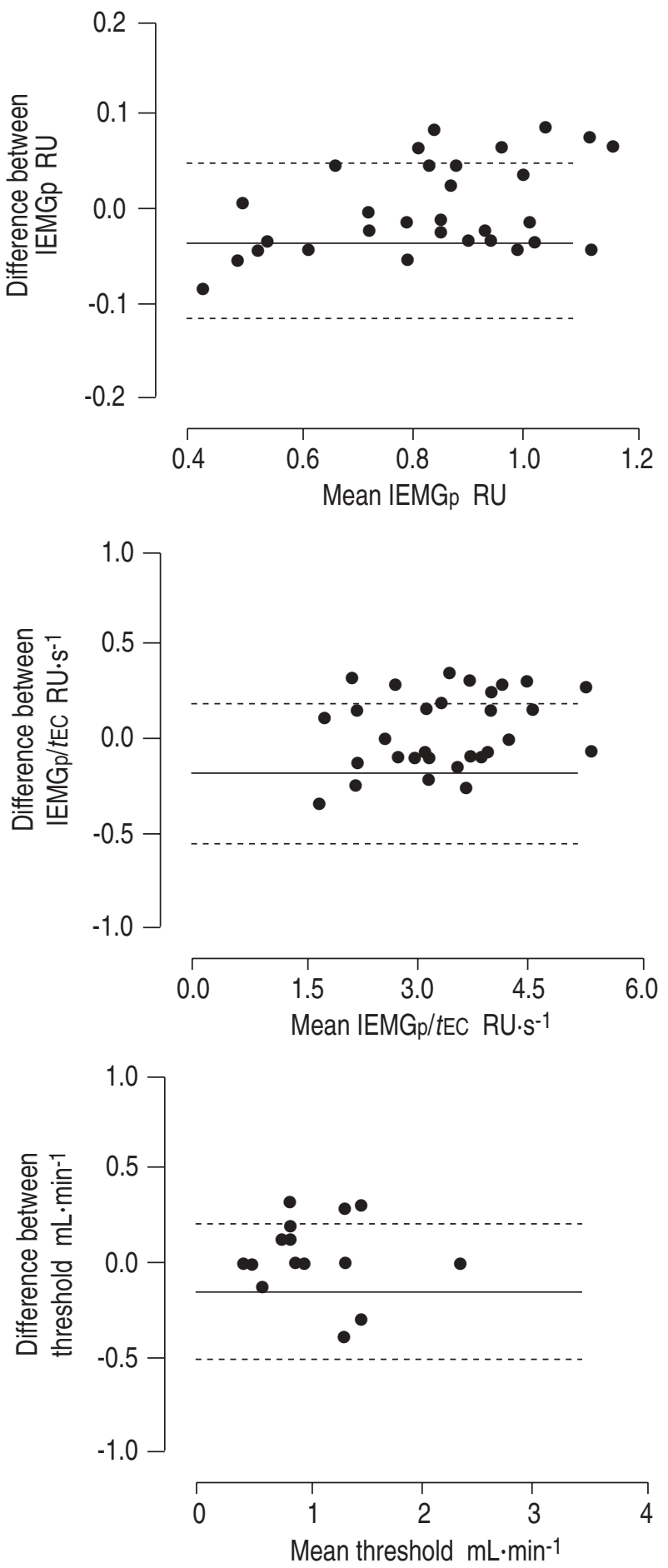

Fig. 2. - Individual differences between values of peak (IEMGp) and slope (IEMGp/tEC) of the electromyographic activity of abdominal muscles (two consecutive $1 \mathrm{~min}$ challenges at threshold level, $n=30$ ), and between threshold values recorded at the first assessment and after 6-9 months $(n=15)$, plotted against their respective mean value. Solid lines represent differences; dotted lines indicate two SD. For definitions see legend to figure 1. 
and IEMGp/tEC values (mean values of the two challenges required to determine cough threshold).

In the 15 subjects selected to evaluate reproducibility of cough threshold, mean threshold values obtained after $3 \mathrm{~h}$ and 6-9 months did not significantly vary with respect to those obtained during the first threshold assessment. Noticeably, individual threshold values obtained after a $3 \mathrm{~h}$ interval turned out to be unchanged in all but one of the nine subjects; in this subject, threshold rose from 2.35 to $2.70 \mathrm{~mL} \cdot \mathrm{min}^{-1}$. Because of the obvious consistency of results, the analysis of repeatability was considered unnecessary in this circumstance. Moreover, comparison of threshold values obtained after 6-9 months showed no significant differences. Median (1st and 3rd quartile) values were 0.80 (0.56 and $1.09)$ and $0.80(0.73$ and 1.24$) \mathrm{mL} \cdot \mathrm{min}^{-1}$, with interquartile ranges of 0.52 and $0.51 \mathrm{~mL} \cdot \mathrm{min}^{-1}$, respectively. Since mean difference between threshold values evaluated at 6-9 month intervals was $0.00 \pm 0.19 \mathrm{~mL} \cdot \mathrm{min}^{-1}$, data could be used to assess repeatability. Repeatability analysis showed that none of the differences exceeded the coefficient of repeatability (fig. 2); individual variability in cough threshold was at the most confined within 1 step change in the nebulizer output.

During voluntary coughs studied in the other group of subjects (n=9), $V^{\prime} \max$ values ranged $3.61-13.63 \mathrm{~L} \cdot \mathrm{s}^{-1}$, and consistently correlated with simultaneously observed IEMGp and IEMGp/tEC values; individual correlation coefficients are presented in Table 1. Maximum expiratory flow during voluntary cough correlated more closely with IEMGp/tEC than with IEMGp values. Correlation coefficients on pooled data for $V^{\prime}$ max versus IEMGp and IEMGp/tEC were $0.57(\mathrm{p}<0.05)$ and $0.71(\mathrm{p}<0.01)$, respectively. In these subjects, inhalation of tussive UNDW outputs of increasing strength led to the appearance of cough motor responses of progressively greater intensity. Statistical analysis revealed a significant, linear relationship between cough stimulus intensity and IEMG

Table 1. - Comparison between Spearman's correlation coefficients $(n=9)$ of peak expiratory flow versus both peak and slope of integrated electromyographic activity during voluntary cough efforts

\begin{tabular}{lcc}
\hline $\begin{array}{l}\text { Ss } \\
\text { No. }\end{array}$ & $\begin{array}{c}V^{\prime} \max v s \\
\text { IEMGp }\end{array}$ & $\begin{array}{c}V^{\prime} \max v s \\
\text { IEMGp/tEC }\end{array}$ \\
\hline 1 & 0.67 & 0.77 \\
2 & 0.48 & 0.80 \\
3 & 0.43 & 0.97 \\
4 & 0.44 & 0.81 \\
5 & 0.53 & 0.82 \\
6 & 0.61 & 0.74 \\
7 & 0.55 & 0.79 \\
8 & 0.67 & 0.65 \\
9 & 0.47 & 0.86 \\
\hline Median & 0.55 & 0.80 \\
1st, 3rd Q & $0.47,0.55$ & $0.77,0.81$ \\
IQ range & 0.08 & 0.04 \\
p-value & & $<0.01$
\end{tabular}

Ss: subjects; $V^{\prime} \max$ : maximum expiratory flow; IEMGp: peak integrated electromyographic activity of abdominal muscles; $t$ EC: duration of the integrated electromyographic ramp; 1st, 3rd Q: 1st and 3rd quartile; IQ range: interquartile range. \#: according to Wilcoxon's signed rank test.

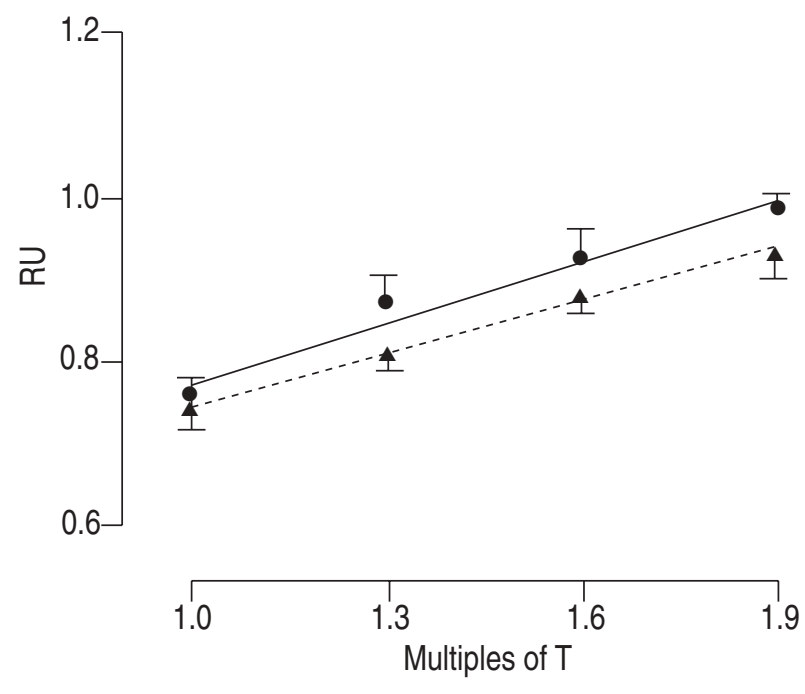

Fig. 3. - Relationship of $\operatorname{IEMG}_{\mathrm{p}}(\bullet)$ and $\mathrm{IEMG}_{\mathrm{p}} / \mathrm{tEC}(\boldsymbol{\Delta})$ and cough stimulus intensity expressed as a multiple of individual cough threshold values $(\mathrm{T})$. Pooled data from nine subjects. Data are presented as mean \pm SEM. $\perp: r^{2}=0.754 ; p<0.01 ;---: r^{2}=0.752 ; p<0.01$. For definitions see legend to figure 1 .

variables in each subject. Regression coefficients (pooled data) of cough stimulus intensity versus IEMGp and IEMGp/tEC (fig. 3) were $0.754(\mathrm{p}<0.01)$ and $0.752(\mathrm{p}<0.01)$, respectively.

\section{Discussion}

The main results of the present study show that cough threshold to UNDW inhalation can be measured fairly accurately in the responders with a high degree of repeatability, and that the force developed by contracting muscles during cough can be reliably assessed through IEMG activity of abdominal muscles; at threshold stimulus intensity, IEMGp and IEMGp/tEC are highly repeatable. A dose-response relationship has been found between the nebulizer output and the magnitude of IEMG variables of the expiratory thrusts evoked. Furthermore, $V$ 'max correlates with IEMGp and, even more closely, with IEMGp/ $t$ EC during voluntary cough efforts.

Despite the relatively large number of subjects tested in the present study, the percentage of nonresponders (17\%) was small when compared with that (25-30\%) reported in previous investigations $[6,10]$. This discrepancy may be related, at least in part, to the mode of aerosol administration [10], or the interposition of a respiratory valve between the nebulizer and subjects' airways $[6,7]$.

Very few previous attempts have been made to evaluate cough threshold to hypotonic stimuli and, in particular, to UNDW inhalation [8, 10]. With the method presented here, even though stimulus intensity has not been varied along a continuum, but in steps, the latter appear to be smaller than those employed in previous studies $[8,9]$ and, in any case, sufficiently small to allow an accurate assessment of the threshold level. In addition, the high short- and long-term reproducibility of cough threshold measurements suggests that this variable may represent a useful tool for quantification of the sensitivity of the subjects to the stimulus adopted. 
We believe that the inhalation tests performed in the present study were sufficiently standardized to provide reliable results. Nevertheless, several lines of evidence have indicated that very large variations in the mode of aerosol inhalation, namely in the inspiratory time, inspiratory volume and, especially, in the inspiratory flow rate, may affect the penetration of particles and their site of deposition within the airways, hence affecting the bronchial response $[22,23]$. Thus, it may be questioned whether differences in the breathing pattern between subjects or, more importantly, changes in respiratory variables induced by UNDW inhalation in the same subject may have influenced our assessment of cough threshold. However, this seems unlikely in the present experimental conditions, and the conclusions are in agreement with previous studies [22, 23]. Airway deposition of saline aerosol does not vary significantly in relation to minor variations in the pattern of breathing, either in normal subjects [24] or in patients with obstructive pulmonary disease [25]. Furthermore, UNDW inhalation has only minimal effects on the breathing pattern in normal subjects [26]. Thus, we chose to avoid the stress due to the imposition of a predetermined pattern of breathing in our subjects.

Previous methods of quantifying cough responses based on cough frequency have been widely used and can provide valuable information $[4,6,7,14]$. However, they are limited, as they treat all coughs as equal and do not allow an evaluation of the strength of expiratory thrusts. Other methods using, for instance, expiratory flow $[2,6]$, or cough noise [2], have been discarded. Measurements of expiratory flows require the use of a pneumotachograph and a respiratory valve. Since any device interposed between the nebulizer and the airways may, potentially, affect the size and penetration of inhaled particles [13], we preferred to avoid this complicating factor. Cough noise can easily be recorded but it has convincingly been shown to bear little relationship to the actual force developed by muscles during coughing [2, 27]. Invasive techniques, such as those required to measure pleural pressure [20], may certainly lead to accurate results but are poorly accepted by patients and even less by control volunteers.

We measured the intensity of motor performance during cough noninvasively from IEMG recordings of abdominal muscles. The tension developed by contracting muscles is proportional to their IEMG activity both under isometric and isotonic conditions [18, 19]. As a consequence, the rate of rise of the force developed (or tension) must be related to that of IEMG activity, namely to IEMGp/tEC in the case of cough efforts. Cox et al. [2] first proposed the use of the EMG activity of the abdominal muscles in the assessment of cough motor responses. However, they suggested the use of "true" integrated activity, i.e. the sum of the total electrical activity during each contraction, instead of the "moving average" of the activity (IEMG), which provides the real time course of IEMG events and allows their appropriate quantitative evaluation. Moreover, at variance with the present experiments, IEMG activity was not normalized to the maximum attainable level in their study. Such normalization is necessary to allow comparisons of IEMG activity between subjects and, in the same subject, between results of separate sessions. The lack of normalization may explain the weak relationship of IEMG with cough flow and volume reported in the study by Cox et al. [2].

More importantly, these authors did not consider the rate of rise of IEMG activity (IEMGp/ $t \mathrm{EC}$ ), which is a very important variable in the present context. As for diaphragmatic activity, this variable can be taken as a valuable expression of the central "drive" to the effector organ [28]. We normalized IEMG activity to the mean peak amplitude recorded during voluntary cough efforts, taken as an accurate estimate of the maximum activity attainable by lateral abdominal muscles. Since the signal amplitude decreases as the distance between fibres and recording site increases [19], we are confident that the recorded EMG signals arose from the obliquus externus and, to a minor extent, from the transversus muscle (see Methods), which are both active during coughing [14, 16]. Moreover, certain muscles of the abdominal wall, such as the obliquus externus muscle, contract slightly more forcibly when engaged in postural rather than during static maximum expulsive efforts performed against a closed glottis [15]. Indeed, in the present study, mean IEMGp values during maximum voluntary cough slightly, but, not significantly, exceeded those recorded during maximum expiratory efforts. In addition, IEMGp values probably do not reflect the activation of a single muscle but, rather, that of different layers of the abdominal wall [14]. Taking into account this consideration and the small variability displayed by IEMGp values during maximum voluntary cough efforts, we believe they are an appropriate and reliable reference for normalization of IEMG data.

The dose-response relationship between stimulus intensity and cough response in terms of IEMGp and IEMGp/ $t$ EC fully characterizes the response to UNDW stimulation [29], and corroborates our results on the reliability of cough threshold. This relationship also suggests that the intensity of reflex motor responses can vary in a relatively narrow range, at least in the present experimental conditions. Reflex cough activation appears to recruit a considerable portion of the contractile mechanism already at threshold level, thus providing a substantial safety factor in airway clearing. However, the limited power of the nebulizer prevented us from describing the entire dose-response relationship in the present study. Further needs of airway clearing may be coped with by little further recruitment of motor units in the contracting muscles and by increasing the number of cough efforts.

To explain the correlations found during voluntary cough efforts, one should keep in mind that the driving pressure during cough and, hence, the expiratory airflow, depends upon the maximum force attained by the contracting muscles and, even more importantly, on the rate of force development during the compressive phase of coughing [20]. Force development is proportional to the IEMG activity of the contracting muscles [18, 19], which accounts for the correlation of $V^{\prime} \max$ with IEMGp especially with IEMGp/tEC during coughing. On the other hand, the relatively weak correlation found between $V^{\prime} \max$ and IEMGp can be related to the fact that during coughing airflow is influenced by many factors besides muscular expiratory efforts [30]; these include lung elasticity and collapsibility, which, in turn, are affected 
by lung volume. Conceivably, these correlations also remain valid during reflex coughs, and corroborate the use of IEMG variables for a quantitative assessment of cough; they also provide a valuable estimate of $V^{\prime} \max$ when the use of a pneumotachograph and/or a respiratory valve must be avoided.

In conclusion, the results indicate that cough threshold to inhalation of ultrasonically nebulized distilled water can be accurately determined, while the intensity of cough motor performance can be reliably and noninvasively assessed by making use of variables such as the peak and slope of abdominal electromyographic activity. We propose that the evaluation of cough threshold as well as integrated electromyographic recordings from abdominal muscles represent useful tools for cough research, especially in patients with neuromuscular disorders characterized by an impairment either in the central motor control or in the effector organ itself.

Acknowledgements: The authors thank J. Collins for helpful advice and E. Guerrin for the English revision of the manuscript.

\section{References}

1. Morice AH, Higgins KS, Yeo WW. Adaptation of cough reflex with different types of stimulation. Eur Respir $J$ 1992; 5: 841-847.

2. Cox ID, Wallis PJW, Apps MCP, et al. An electromyographic method of objectively assessing cough intensity and use of the method to assess effects of codeine on the dose-response curve to citric acid. Br J Clin Pharmacol 1984; 8: 377-382.

3. Stockwell M, Lang S, Yip R, Zintel T, White C, Gallagher CG. Lack of importance of the superior laryngeal nerves in citric acid cough in humans. J Appl Physiol 1993; 75: 613-617.

4. Pounsford JC, Birch MJ, Saunders KB. Effects of bronchodilators on the cough response to inhaled citric acid in normal and asthmatic subjects. Thorax 1985; 40: 662-667.

5. Choudry NB, Fuller RW, Pride NB. Sensitivity of the human cough reflex: effect of inflammatory mediators prostaglandin $\mathrm{E}_{2}$, bradykinin and histamine. Am Rev Respir Dis 1989; 140: 137-141.

6. Higenbottam T. Cough induced by changes of ionic composition of airway surface liquid. Bull Eur Physiopathol Respir 1984; 20: 553-562.

7. Lowry RH, Wood A, Johnson T, Higenbottam T. Antitussive properties of inhaled bronchodilators on induced cough. Chest 1988; 93: 1186-1189.

8. Sheppard D, Rizk NW, Boushey HA, Bethel RA. Mechanism of cough and bronchoconstriction induced by distilled water aerosol. Am Rev Respir Dis 1983; 127: 691-694.

9. Eschenbacher WL, Boushey HA, Sheppard D. Alteration in osmolarity of inhaled aerosols cause bronchoconstriction and cough, but absence of a permeant anion causes cough alone. Am Rev Respir Dis 1984; 129: 211-215.

10. Banner AS. Relationship between cough due to hypotonic aerosol and the ventilatory response to $\mathrm{CO}_{2}$ in normal subjects. Am Rev Respir Dis 1988; 137: 647-650.

11. Higenbottam T, Jackson M, Woolman P, Lowry R, Wallwork J. The cough response to ultrasonically-nebulized distilled water in heart-lung transplantation patients. Am Rev Respir Dis 1989; 140: 58-61.

12. Lavorini F, Fontana GA, Viroli L, Bongianni F, Pantaleo T, Boddi V. Characteristics of the cough response to inhalation of ultrasonically nebulized distilled water in humans. Eur Respir J 1994; 7, Suppl. 18: 25s.

13. Phipps PR, Gonda I. Droplets produced by medical nebulizers: some factors affecting their size and solute concentration. Chest 1990; 97: 1327-1332.

14. Strohl KP, Mead J, Banzett RB, Loring SH, Kosch PC. Regional differences in abdominal muscle activity during various manoeuvres in humans. J Appl Physiol: Respirat Environ Exercise Physiol 1981; 51: 1471-1476.

15. Gandevia SC, McKenzie DK, Plassman BL. Activation of human respiratory muscles during different voluntary manoeuvres. J Physiol 1990; 428: 387-403.

16. Floyd WF, Silver PHS. Electromyographic study of patterns of activity of the anterior abdominal wall muscles in man. $J$ Anat 1950; 84: 132-145.

17. Black LF, Hyatt RE. Maximal respiratory pressures: normal values and relationship to age and sex. Am Rev Respir Dis 1969; 99: 696-702.

18. Bigland B, Lippold OCJ. The relation between force, velocity and integrated electrical activity in human muscles. J Physiol 1954; 123: 214-224.

19. Sharp JT, Hyatt RH. Mechanical and electrical properties of respiratory muscles. In: Macklem P, Mead J, eds. Handbook of Physiology, Respiration, Mechanics of Breathing. Bethesda, MD, American Physiological Society 1986; Section 3, Vol III, Part 2, Chapter 23, pp. 389-414.

20. Leith DE, Butler JP, Sneddon SL, Brain JD. Cough. In: Macklem P, Mead J, eds. Handbook of Physiology, Respiration, Mechanics of Breathing. Bethesda, MD, American Physiological Society 1986; Section 3, Vol III, Part 1, Chapter 20, pp. 315-336.

21. Bland JM, Altman DG. Statistical methods for assessing agreement between two methods of clinical measurements. Lancet 1986; 8: 307-310.

22. Pavia D, Thomson ML, Clarke SW, Shannon HS. Effect of lung function and mode of inhalation on penetration of aerosol into the human lung. Thorax 1977; 32: 194-197.

23. Anderson M, Philison K, Svartengren M, Camner P. Human deposition and clearance of 6-micron particles inhaled with an extremely low flow rate. Exp Lung Res 1995; 21: 187-195.

24. Ryan G, Dolovich MB, Obminski G, et al. Standardization of inhalation provocation tests: influence of nebulizer output, particle size, and method of inhalation. $J$ Allergy Clin Immunol 1981; 67: 156-161.

25. Phipps PR, Gonda I, Anderson SD, Bailey D, Bautovich G. Regional deposition of saline aerosols of different tonicities in normal and asthmatic subjects. Eur Respir $J$ 1994; 7: 1474-1482.

26. Chadha TS, Birch S, Allegra L, Sackner MA. Effects of ultrasonically nebulized distilled water on respiratory resistance and breathing pattern in normals and asthmatics. Bull Eur Physiopathol Respir 1984; 20: 257-262.

27. Hsu JY, Stone RA, Logan-Sinclair RB, Worsdell M, Busst CM, Chung KF. Coughing frequency in patients with persistent cough: assessment using a 24 hour ambulatory recorder. Eur Respir J 1994; 7: 1246-1253.

28. Milic-Emili J, Whitelaw WA, Grassino AE. Measurement and testing of respiratory drive. In: Hornbein TF, ed. Regulation of Breathing. Part 2. New York, Dekker, 1981; pp. 675-743.

29. Orehek J, Gayrard P. Nonspecific bronchial provocation tests in asthma. Bull Eur Physiopathol Respir 1976; 12: $565-598$.

30. Arora NV, Gal TJ. Cough dynamics during progressive expiratory muscle weakness in healty curarized subjects. J Appl Physiol: Respirat Environ Exercise Physiol 1981; 51: 494-498. 